\title{
Cross-discipline investigation of the relationship between academic performance and online resource access by distance education students
}

\author{
Andrea Crampton ${ }^{\mathrm{a}, *}$, Angela T. Ragusa ${ }^{\mathrm{b}}$ and Heather Cavanagh ${ }^{\mathrm{a}}$ \\ ${ }^{a}$ Faculty of Science, Charles Sturt University, Wagga, Wagga, Australia; ${ }^{b}$ School of Humanities \\ and Social Science, Charles Sturt University, Wagga, Wagga, Australia
}

(Received 14 March 2011; final version received 30 June 2011)

\begin{abstract}
Educational technology implementation often owes more to the technical proficiency of the teaching staff and/or the capacity of the institution than to a student outcome-centred design process. Creation of online resources takes considerable time and involves significant cost to both the institution, for devices and platforms, and to students for devices and Internet connectivity charges. Here, we present a cross-discipline investigation of student engagement with a range of simple resources. Our aim was to determining if the provision of such resources had an impact on student academic performance regardless of the students' level of academic proficiency. This research focused on students studying first-year introductory subjects at a distance (off campus) from two different faculties, Arts and Science. Analysis of the web access data from the learning management system (Sakai) demonstrated that students who accessed the most resources in terms of diversity and percentage of available resources achieved higher grades. We postulate that the resources prompted students to spend more "time-on-task" and facilitate more active styles of learning. We suggest, however, that students need to be made aware of the value of the resources and how they are best used to enhance academic performance.
\end{abstract}

Keywords: distance education; online resources; academic performance; virtual learning environments; e-learning

\section{Introduction}

The shift from an industrial to an information-driven society (Castells 2000) has substantially changed education delivery, often facilitated by the use of internetdriven communications that are a recent, yet foundational, component of many educational systems (Schifter 2004). The globalisation of world economies and internationalisation of curricula (Barjis 2003) fostered an environment, whereby universities increasingly are internet dependent. As e-learning supplements, and even supplants, traditional classroom learning environments (Ragusa 2009), universities compete to lead in flexible delivery, to achieve market dominance and to meet government policy objectives (Ragusa 2007). In response, higher education educators are encouraged to augment online delivery resources and align their teaching practice with the needs and expectations of twenty-first century learners and markets.

*Corresponding author. Email: acrampton@csu.edu.au 


\section{A. Crampton et al.}

Technology-infused distance education is the fastest growing sector in education (Tennant, McMullen, and Kaczynski 2009). A range of socio-economic factors is responsible for this growth. Distance education requires less physical infrastructure and resources and can offer students access to higher education for a reduced living cost (Betts, Hartman, and Oxholm 2009). Distance education enables institutions to access a global student market (Tennant, McMullen, and Kaczynski 2009) that extends to non-traditional populations, particularly those with family and/or work obligations that prevent attendance at university campuses (Betts et al. 2009). Furthermore, distance education is material to the heightened global interest in higher education and the growth in international students (Ragusa and Steinke 2011). These economic realities, coupled with the growth in size and acceptance of online education, and the introduction of widely available, public access, educationassociated social media (e.g. iTunes $\mathrm{U}^{1}$ ) clearly signal that technology-dependent learning is as much a part of twenty-first century education as the chalk board was in classrooms of yesteryear.

The changes fuelled by these economic realities, however, are underscored by a deeper socio-historical shift. In contrast with past societies' reliance on face-to-face communication, rapid changes in how we interact today, "for the first time in human history" (Giddens 1984, 185), made possible by technology led us to shift from a local to inherently global social organisation. Giddens' later works (1991, 1994, 2002) helped us to theoretically frame how education pedagogies, informed by communicative technologies, exist in a social order characterised by different traditions, identities, expertise and global relations.

Epistemic and technical shifts in how individuals relate to one another have, however, raised some concerns in the higher education sector, including how the mechanism for social interaction and communication affects learning outcomes. Questions regarding the effects such changes have on the educational experience of students are but one example of issues facing contemporary consumers of knowledge in societies, where specialised expert knowledge replaces traditions to grant or deny power and authority (Giddens 1991). Alongside, macro level social changes are relentless micro level, everyday shifts that determine our technical proficiency. In the case of education, the focus on technical solutions can translate into poorly designed or executed resources that waste both educators' and students' time, the latter of which might have been better spent on traditional learning tasks, such as textbook reading. Conversely, educators who are less enthusiastic about educational technologies may feel that their expertise and authority are threatened by a lack of technical command in an increasingly technical environment. Given the ever-evolving plethora of educational technology platforms, tools and resources ("bells and whistles") presented to the academic community, it is easy to lose sight of core educational goals. A specific educational goal that we investigate in this article is the enhancement of learning environments to facilitate students' acquisition of substantive and tacit knowledge.

A growing body of educational technology research, however, is beginning to question whether the twenty-first century bells and whistles enabled by educational technologies drown, or at least distract from, sound pedagogy. According to McFarlin (2008), for educational technology to be effective, student learning and outcomes must be the focus of its implementation and use. Pedagogies with technologies driven by learning outcomes are increasingly noted in the literature (see Tennant, McMullen, and Kaczynski 2009) with Larson and Chung-Hsien (2009) 
concluding that the delivery mode is irrelevant so long as the instructor applies "best practices".

The present study seeks to fill knowledge gaps in the research literature by examining how and if the use of pedagogically driven technologies enhances or detracts from higher education delivery in two large and diverse introductory subjects at an Australian University. By providing an evaluation of online communication and resources used by distance students in a range of natural and social science courses, as well as the humanities, our research sample includes students with widely varying pre-tertiary performance abilities that we term 'perceived academic capacity'.

\section{Background}

The resources and communication tools used to teach in two subjects, introductory microbiology (MIC) and introductory sociology (SOC), provided students with dynamic learning environments not traditionally available to geographically dispersed distance students. The design and application of learning resources mimicking those of traditional face-to-face classrooms, we argue, represents real progress, not the step sideways that those critiquing blended learning approaches claim (Morrison 2003; Tremblay 2006). Traditionally, students studying by distance education (the "DE cohort" of each course) receive a paper-based subject outline containing details of assessment procedures, a recommended study pattern and a study guide with key explanations from the textbook and some additional figures and explanations written by the teaching staff. Here, we examine the effectiveness of the use of virtual lectures, access to lecture handouts and student use of asynchronous forums on the education outcomes of students as measured by their final grade and analysed by measuring activity logs from the learning platform for the entire teaching session.

Due to large enrolment numbers (SOC $N=145$ and MIC $N=221$ ), the online space mirrored a more traditional didactic classroom, where students passively received information, albeit via virtual lectures (narrated slides) or electronic handouts, rather than live lectures or tutorials. This structure is commensurable with other initial forays into online education (Tennant, McMullen, and Kaczynski 2009) that rely on familiar, normative pedagogies (i.e. we start with what we know) and are based on materials developed for face-to-face environments (Salter, Pang, and Shrama 2009). Both subjects used an electronic forum structured similarly to the "question and answer" sessions that often accompany face-to-face lectures and/or tutorials. Unlike many other studies of online or blended learning, we examine subjects previously taught only by correspondence (see Schifter 2004), where students had no opportunity to attend lectures, with the exception of a compulsory 4-day residential school on campus for the microbiology students to learn practical laboratory skills.

While the provision of online resources replicating traditional classrooms may not initially seem conducive to increasing student engagement, the platform context (i.e. resource hosting plus synchronous and asynchronous communication tools) enhances opportunities for student interaction with the content and with each other beyond those possible in conventional classrooms. The online platform also allows distance education students to interact with on-campus students. Therefore, provision of online resources, with their capacity to facilitate interactions, can be viewed as an intermediate step between lecture-based delivery and the proposed ideal, student-centred teaching model designed around active or problem-based 


\section{A. Crampton et al.}

learning (Exeter et al. 2010). This transitional step is, perhaps, a suitable option to engage first-year students, most of whom enter university environments from the more traditionally didactic background of secondary schooling, although this is likely to change in the future as online learning becomes more prominent in the high school system (Drabinski, Clark, and Roberts 2011). With universities' increased reliance on self-directed learning, this transitional step may assume even greater importance, particularly for students studying by distance. Clearly structured higher education learning environments, with resources such as audio lectures or lecture notes, can provide students clear signposts likely to further facilitate transition towards self-directed learning. This transition step will no doubt evolve as pedagogic practices of secondary schools and other educational institutes that increasingly adopt the use of blended learning. Movement from an online environment replicating traditional classrooms towards an effective blended environment with active learning and engagement requires professional development for teaching staff and training for students (Salter, Pang, and Sharma 2009). Thus, the re-socialisation of staff and students is a necessity and likely to be affected by familiarity and use of blended learning in prior organisational settings.

The learning environments examined were not open learning environments as defined by Clarebout and Elen (2008); students were neither able to manipulate their learning environment nor presented with meaningful problems to solve. As distance students, a high degree of self-regulation was assumed and considered necessary for academic success (Barnard-Brak, Lan, and Paton 2010). The degree of selfdirectedness, or self-regulation, required from distance learners is a major risk factor for attrition (Rovai and Downey 2010). While direct measures of selfregulation have been applied in educational settings (Biesinger and Crippen 2010), sociological studies focused on how interventions, such as the structure and design of learning environments, affect learning outcomes, are required to complement studies of psychological characteristics such as those noted above. Robinson's (2007) sociological study, for example, noted how Giddens' structuration theory can inform e-learning design and the value of providing multiple communication tools to students as a way of enhancing students' agency in affecting their academic goals.

Most modern learning management systems (LMS) provide at least one simple measure of student access to, and use of, learning resources. Use of learning resources offers an indicator of students' capacity for self-regulation accessible by an audit file, most commonly in the form of a log tool. Web logs, as indicators of students' study practices, have been used in a variety of ways. Our research builds on prior research, such as Judd and Kennedy's (2010), 5 year analysis of web use at dedicated computers, which found that students predominantly accessed the university's core systems and learning resources posted through the internal system rather than external sites and tools. This behaviour, however, was exhibited only by advanced students because most courses utilised the university's LMS (Judd and Kennedy 2010). Log files were also used to investigate the pace of 6112 students' learning in a fully online environment to examine resource type and use in relation to time of day and duration of access (Hershkovitz and Nachmias 2009) as well as to map embedded versus non-embedded support tool use and student self-regulation (Clarebout, et al. 2010).

Generally, the use of log files allows researchers to examine "real world" practices (Schrader and Lawless 2007), instead of conducting lab-based scenarios and other 
more intrusive instruments such as surveys. Hence, this technique is ideal for exploratory analyses of students' LMS use, permitting creation of appropriate interventions or variations in design that can improve learning resource effectiveness. Log files matched with assessment of learning outcomes, such as grades, are useful for examining students' initial resource use to see how and if this affects academic performance as well to explore the impact of intervention strategies applied during the teaching session. Moreover, the collection of log data is suitable to large classes for which surveys, focus groups and other more intrusive or intensive methodologies are less feasible.

\section{Methods}

The primary research aim was to examine the effect of providing online learning resources on students' academic performance. To minimise the impact of subject type and student cohort, we chose subjects from two different faculties containing students with varied levels of pre-tertiary academic performance and preparation for university study. Secondary data, available from university subject site logs, student grades and learning forum logs, were compiled to reflect student utilisation of online learning resources and quantitatively analysed.

\section{Sample and design}

The research sample consisted of two large, first-year introductory subjects taught between August and December 2009. The subjects spanned two divergent faculties, Science and Arts. The first subject, SOC, was taught by distance only, contained 145 students and was primarily taught by a teaching assistant under the management of a senior academic who designed and produced the subject content and learning resources. The second subject, MIC, was taught both internally (on campus) at two different locations (400 km apart) and simultaneously by distance education, containing a total of 593 students. MIC was taught by a single academic at one campus, and by nine academics at the other. All cohorts were supported by a single online platform managed by the academic staff. The 221 students studying MIC by distance travelled to one campus for a 4-day residential school to complete the laboratory component of the subject, whilst the SOC students were not required to attend any on-campus sessions.

The assessment requirements varied with each subject. SOC students were required to complete three assessment items: an online mid-semester multiple choice exam, a 1000 word essay and an invigilated paper-based exam at the end of the semester. MIC students were assessed by weekly quizzes on laboratory topics, a midsemester and an end-of-semester exam, both of which contained multiple choice and short answer questions. This investigation examines the distance students enrolled in both of these subjects.

\section{Online platform and learning resources}

Both MIC and SOC used a customised version of the Sakai platform, termed 'Interact', plus an additional forum tool for asynchronous communication. In both subjects, the forums were divided into a "general" forum and "sub-forums" that related to each topic taught ( 9 for MIC and 11 for SOC). Administrative tasks, such 


\section{A. Crampton et al.}

as the organisation of residential schools (MIC) and general queries (SOC), were managed utilising the general subject forum.

Students in SOC were provided with PowerPoint slides summarising the chapters of the textbook and providing additional sociological information. These slides were linked to separate virtual lectures produced using Adobe Captivate ${ }^{\mathcal{C}}$ (v3). The virtual lectures were provided in both shockwave and.exe formats and contained the lecturer's narration of key introductory concepts. MIC students were also provided PowerPoint slides. Their slides, however, were the same as those presented to the subject's internal students during campus lectures and textbook-based tutorial exercises. Both subjects also provided the students with a printed subject outline and study guides (Figure 1).

\section{Analysis of resource use}

The Sakai platform included a log tool (SiteStats) used to generate data about which resources were accessed by each student. It is important to note that SiteStats only records access to the resources and not use of the resource. Hence, some resources may have been accessed but not viewed. Actual reported use of the resources was not assessed by a student survey because of the typically low student survey response rates at the university being sampled. Use of secondary data permitted reliable analysis of the entire sample's performance and each student's resource access, rather than perceived use from social surveys.

Students' forum participation was analysed by counting the number of messages each student posted on each forum. Furthermore, overall forum use was calculated using an inbuilt statistics tool for forum evaluation. Analysis of individual student use of forums and resources was conducted after final grades were announced; a procedure approved by the School of Biomedical Science's Human Ethics Committee, approval 406/2009/12.

Student resource use and grades were entered into cohort-specific SPSS data files and analysed separately by subject to produce descriptive statistics and correlations. $T$-tests were conducted with significantly correlated $(p=<0.05)$ variables using the independent sample $t$-test with Levene's test for equality of variances, where equal variances were assumed.

\begin{tabular}{|lcc|}
\hline Resource Type & MIC & SOC \\
\hline $\begin{array}{l}\text { Virtual Lectures (voice over PowerPoint slides } \\
\text { created by lecturer) }\end{array}$ & $\mathrm{X}$ \\
\hline PDF of Lecture Slides & $\mathrm{X}$ & $\mathrm{X}$ \\
\hline $\begin{array}{l}\text { PDF or Word files with tutorial activities (i.e. } \\
\text { quizzes, games, key questions) }\end{array}$ & $\mathrm{X}$ & $\mathrm{X}$ \\
\hline General Discussion Forum & $\mathrm{X}($ nine) & $\mathrm{X}$ (eleven) \\
\hline Content-Specific Forums &
\end{tabular}

Figure 1. Types of resources provided to each cohort of students. 


\section{Results}

One hundred and nine SOC students and 181 MIC distance students completed all the requisite tasks to receive a final grade. Descriptive statistics revealed that $51 \%$ of MIC and $46 \%$ of SOC students posted messages on the general forums. Only $8 \%$ of the SOC students and $20 \%$ of the MIC students posted messages on topically related sub-forums. At least one virtual lecture was downloaded by $71 \%$ of the SOC students and $12 \%$ downloaded all virtual lectures. The PowerPoint slide files were accessed by $81 \%$ of the SOC students, with $9 \%$ downloading all of them. Five students $(5 \%)$ accessed at least one slide file but none of the virtual lectures. Conversely, 14 students $(13 \%)$ accessed at least one virtual lecture but none of the slide files. Lecture slides were downloaded by $88 \%$ of the MIC students, with most of those $(84 \%)$ also accessing at least one tutorial resource. Sixteen percent of the MIC students accessed all available tutorial resources.

In MIC, weak yet significant positive correlations (i.e. the higher a student's grade, the more resources he or she accessed) were found between a student's final grade and his or her downloading lecture slides $(r=0.28 ; p=0.00)$ or accessing tutorial resources $(r=0.31 ; p=0.00)$ and/or posting to the content forums $(r=0.34$; $p=0.05$ ). In SOC, a moderately strong and significant correlation existed between students accessing the virtual lectures and their final grade $(r=0.40 ; p=0.00)$. In other words, those students in both subjects who downloaded electronic learning resources were more likely to receive higher grades. No significant correlations were observed between students' contribution to subject forums and final grades in SOC, indicating that lecture slides may be of greater utility to learning that subject's content than forum communication. It is important, however, to note that correlations do not determine causality. Therefore, to test if the correlation between learning material usage and final grades is statistically meaningful, parametric tests of significance were conducted.

After tests for normality confirmed that the samples were normally distributed, two-tailed independent groups $t$-tests were conducted to test the means between the two subjects related to resource use and final grades. Findings revealed a significant difference in the final grades between SOC students who received at least a pass $(\mathrm{M}=$ 9.40, $\mathrm{SD}=4.59)$ and those who failed $(\mathrm{M}=5.24, \mathrm{SD}=4.72)$ related to the access of virtual lectures $t(133)=5.22, p=0.00$. In other words, the more virtual lectures accessed, the higher SOC students' final grades. These significant relationships are evident in Figures 2, 3 and 5.

Similar analyses of resource use by the MIC students revealed four significant relationships, the strongest related to students' access of tutorial resources and general forum usage, the latter in contrast to the SOC students. Students who failed in the subject accessed fewer lecture slides $(\mathrm{M}=8.75, \mathrm{SD}=3.83), t(156)=2.020, p=$ 0.05 , than students who received at least a passing final grade $(\mathrm{M}=10.45, \mathrm{SD}=4.09)$. Students with at least a passing final grade $(\mathrm{M}=9.98, \mathrm{SD}=12.98)$ posted more messages on the general forum, $t(89)=1.95, p=0.00$, than students who failed $(\mathrm{M}=$ $3.14, \mathrm{SD}=3.23)$. Students who failed in the subject also accessed $(\mathrm{M}=1.00, \mathrm{SD}=$ 0.67 ) the subject content forums less frequently, $t(40)=2.05, p=0.05$, than students with a passing grade or better $(M=2.34, S D=2.03)$. Finally, students with at least a passing final grade accessed more of the tutorial resources $(\mathrm{M}=12.95, \mathrm{SD}=6.77)$, $t(150)=2829, p=0.01$, than students who failed $(\mathrm{M}=8.75, \mathrm{SD}=3.83)$. 


\section{A. Crampton et al.}

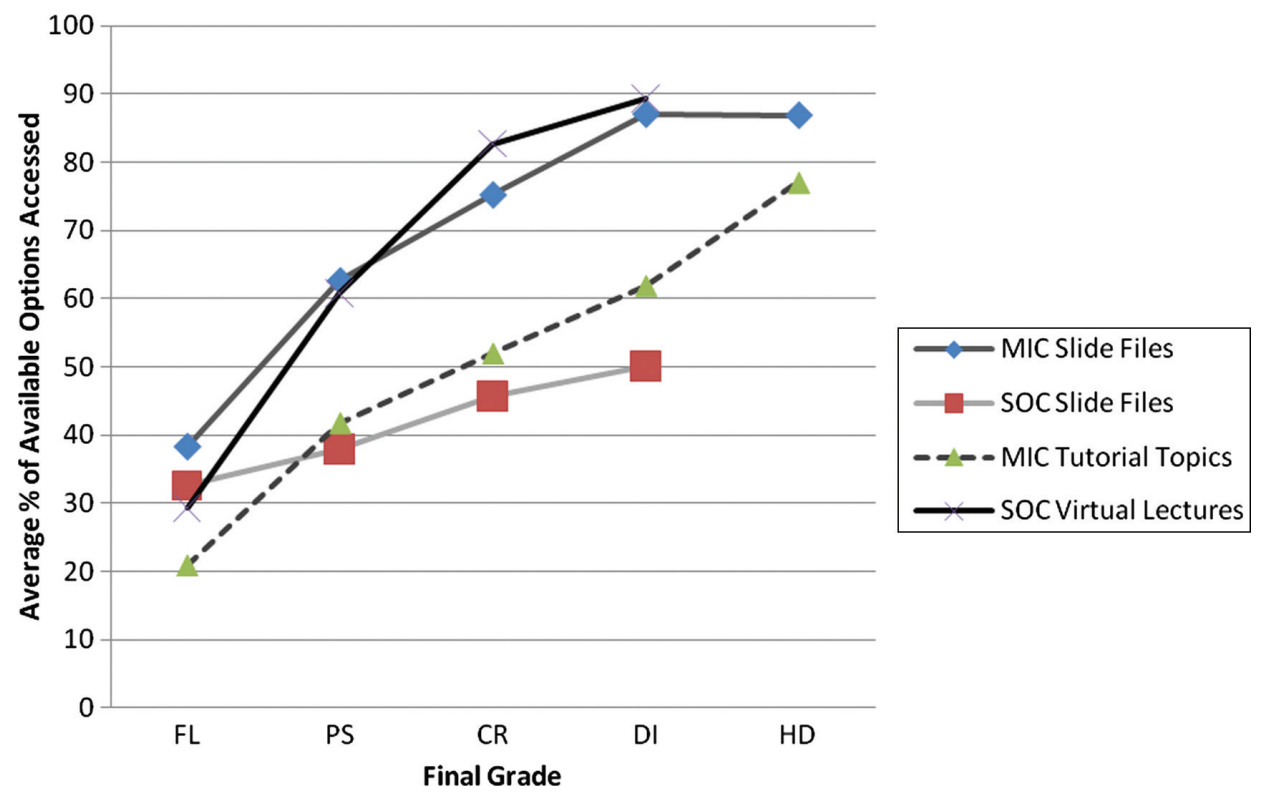

Figure 2. Average percentage of an available resource type accessed by students relative to their final grade. FL, fail; PS, pass; CR, credit; DI, distinction; HD, high distinction.

\section{Discussion}

Our research reveals that the provision of online resources to distance education students supports learning outcomes and improves academic performance. The finding that the majority of students accessed lecture slides was anticipated

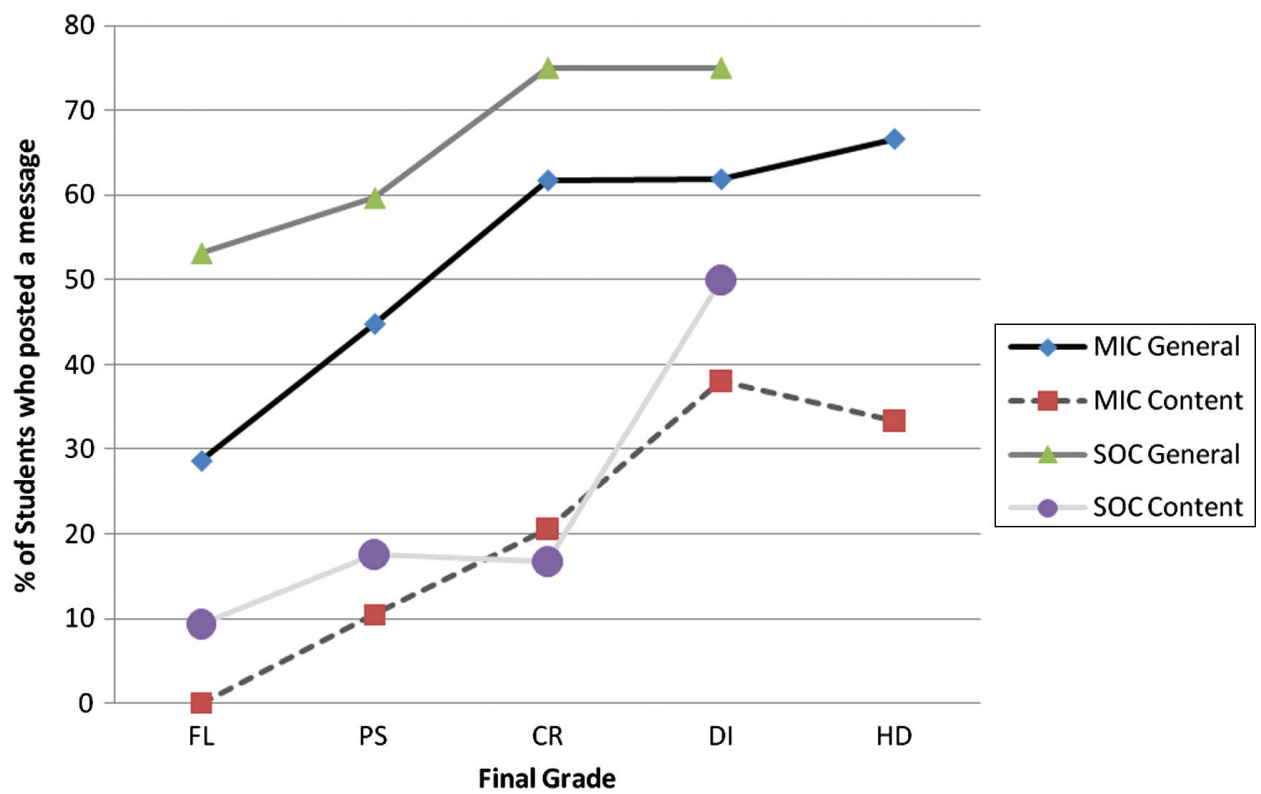

Figure 3. Percentage of students who posted a message on either the general or contentspecific forums, relevant to their final grade. FL, fail; PS, pass; CR, credit; DI, distinction; HD, high distinction. 


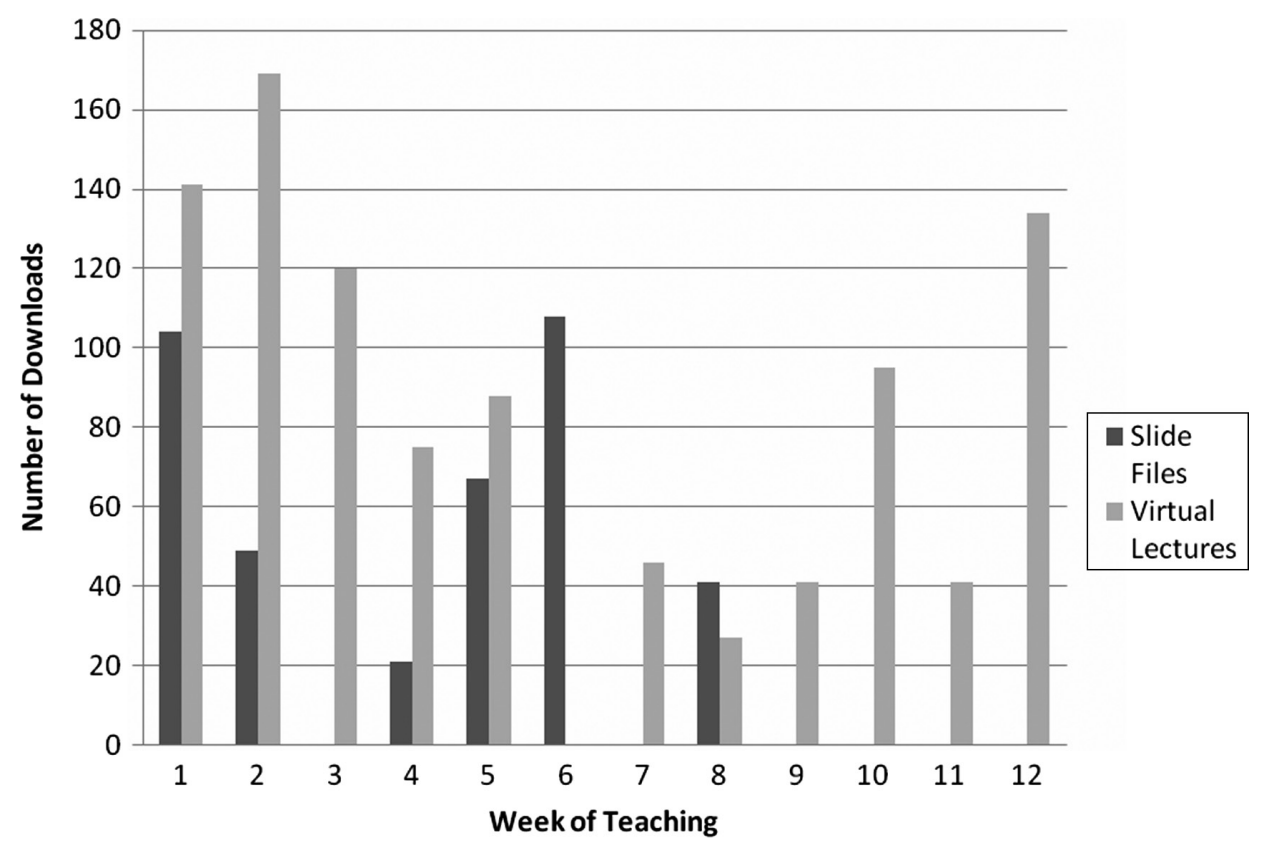

Figure 4. Download patterns for virtual lectures and slides by 101 SOC students during the 12 weeks of the semester.

because such activity replicates face-to-face classroom practices, such as note taking. Figure 4, however, presents an unanticipated finding: SOC students eventually stopped downloading lecture slides but continued to access the virtual lectures that represent a much larger commitment in terms of time and download time/cost. Students' preference to use virtual lectures alone, particularly as audio files in a MP3 format, rather than PowerPoint slides coupled with audio, reveals a shift in learning preference made possible by recent advances in communication technology. Student comments from subject evaluations revealed that MP3 files were preferred because of their transportability and use in multi-tasking scenarios such as while driving, commuting, doing household tasks, etc. Given the poverty of time experienced by many distance education students, it is possible that those who accessed the MP3 files were more likely to use them, than those who only accessed the PowerPoint slides. Accessing virtual lectures fostered better comprehension of subject content and concepts as evidenced by higher academic achievement (see Figures 2 and 5) than accessing PowerPoint slides alone. The virtual lectures ensured students who are audio learners, or potentially just busy, could engage with the content in a manner that fitted their learning style and/or lifestyle; a delivery mode unavailable to distance students because institutions stopped posting correspondence courses on tape.

The degree to which students access online learning opportunities is a potential indicator of how prepared they are for self-regulated education fostered by online platforms. For some students, however, the transition from seeking knowledge out of casual interest to taking a disciplined approach towards reaching a concrete learning goal, such as a final grade, may be less readily adopted during their first year of university study if left entirely up to their independent pursuit. Help-seeking behaviour is regarded as a significant component of effective self-regulated learning. 


\section{A. Crampton et al.}

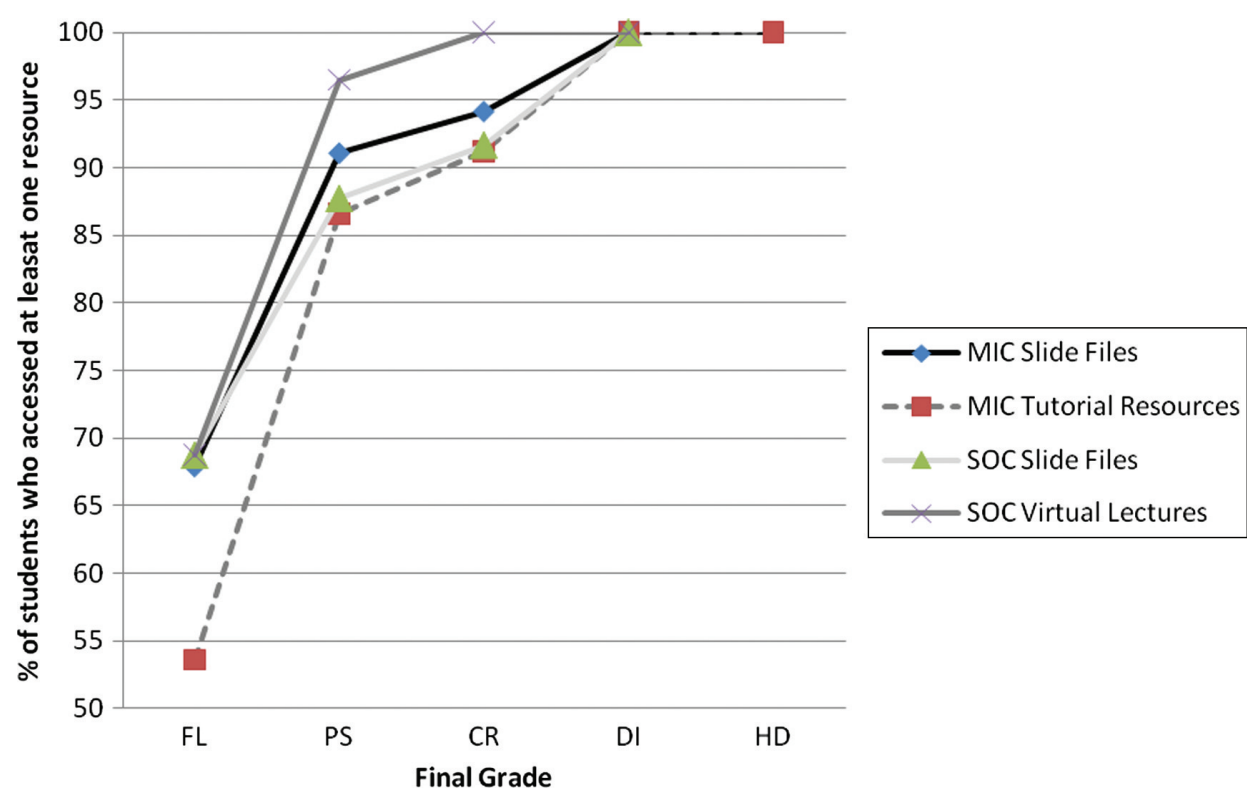

Figure 5. Percentage of students who accessed at least one of the available resources relevant to their final grade. FL, fail; PS, pass; CR, credit; DI, distinction; HD, high distinction.

Students who choose to study via distance education are expected to have a high degree of self-efficiency (Barnard-Brak, Lan, and Paton 2010) and be able to regulate their learning environment around other life issues. Indeed, Barnard-Brak, Lan and Paton (2010) noted even competent self-regulators who "do what it takes...to achieve well in their learning but they don't do much more" (Barnard-Brak, Lan, and Paton 2010, 72) are able to achieve academic success. Our results indicate students who actively sought help and/or clarification for issues, by way of forum postings, achieved higher levels of academic success (Figure 3). That is not to say students who read forums without posting contributions, otherwise known as "lurkers" (Bax and Pegrum 2010), are less effective at self-regulated learning; "lurking", as prior sociocultural research found, may simply reveal that help-seeking needs can be met by passive engagement. Our focus on first-year subjects demonstrates that students may be affected by their level of academic socialisation. This supports prior research findings that first-year students may not understand the value of support mechanisms provided or have the capacity to use them adequately (Azevedo, Cromley, and Seilbert 2004).

Identification of key attributes used by skilled self-regulators is one way universities can develop better support and training systems, particularly for nonself-regulators. Enhanced support and training may lead to better outcomes such as academic performance and completion rates. Many current learning environments that give students control over access to support devices require them to be good selfregulators and aware of the full potential of the provided resources, before they can adequately access or identify any support they may need (see Clarebout et al. 2010). Enhancing the support provided to help students become better self-regulated learners from the time they enter university is crucial to address the long-term nature of goal orientation and self-regulation, which requires more than one teaching session to affect (Biesinger and Crippen 2010). The role of the educator is changing 
from one who simply possesses and imparts knowledge to one who facilitates the development of learning skills that show students how to obtain and interpret knowledge (i.e. the shift from didactic styles of early e-learning to c-learning ${ }^{2}$ ) (Ledzinska and Postek 2010; Tan, Wang, and Xiao 2010). We need to consider the implications of changing roles when examining the development and use of nontraditional learning tools. The overestimation of students' capacity to use the technology provided appropriately (Kvavik 2005; Nasah et al. 2010) is an area of particular concern and a possible confounding factor in how the resources in our study were applied. Furthermore, lack of appropriate technical support for distance students studying online is a major contributor to attrition (Rovai and Downey 2010) and a common criticism noted by distance students at our institution.

Accessing tutorial resources (MIC) or virtual lectures (SOC) was positively correlated with improved academic performance as illustrated in Figure 2. Both of these resource types simulate the same key practice, namely time on task (i.e. the amount of time a student spends engaged with a resource or activity). Grimstad and Grabe (2004) noted that students who accessed online tutorial exercises (in their case quizzes) performed better academically than those who did not. They concluded that although quizzes gave students experience with the types of questions in the examination, it was the time spent on the quizzes that possibly explained their correlation with academic success (Grimstad and Grabe 2004). Similarly, Kuh (2004) noted, in relation to student development, that the amount of time devoted to "educationally purposeful activities" was the best predictor of students' learning outcomes. In regards to microbiology, Johnson (2008) found a significant correlation between academic performance and use of online resources (again quizzes), attributing that time-on-task may be a key component of the association. Furthermore, a meta-analysis of online learning studies conducted by the US Department of Education concluded that time-on-task was the only statistically significant aspect of online learning affecting student performance, noting that online students who spent more time-on-task fared better than their counterparts studying in the traditional face-to-face mode (US Department of Education 2009). Our research adds further support that purposive online learning activities positively affect student performance.

The online tutorials and virtual lectures provided students in our study a vehicle to interact with each subject's content in more than one way, encouraging active learning via completing tutorial exercises and discussion questions. Use of these resources required students either to work through problems or to answer questions that involved connecting content and concepts in a manner not presented in the core materials provided. Active learning promotes better engagement with subject matter (Windham 2005), an important factor in student success and retention (Sheard, Carbone, and Hurst 2010). Nevertheless, the value of active learning, and its effect on student outcomes, remains a contentious, unresolved issue with the perceived benefits potentially attributable to a time-on-task effect as previously noted (US Department of Education 2009).

\section{Conclusion}

Our research evidenced that the provision of low-cost and easy-to-create online resources quantitatively enhanced students' academic performance: students who accessed the online resources achieved greater academic success. This is notable given 


\section{A. Crampton et al.}

that the institutional cost of providing the supplemental electronic resources was limited to the purchase price of the software (Adobe Captivate ${ }^{\odot}$ v.3) and a limited time investment for staff training with minimal impact on staff time. For example, apart from up-skilling in software use, MIC staff required no additional preparation time, as they simply uploaded online versions of resources already created for the face-to-face class. Conversely, SOC staff spent an additional hour per week to create the lecture slides, record them and upload them; however, these resources could then be reused for multiple sessions.

The relationship between resource access and academic success was related to both the diversity of available resources and the proportion of each type accessed by the student. Such findings may be informed by the sociological theory of Giddens, specifically his work on culture and structuration theory that, as contextualised by Robinson (2007), suggests that the provision of a range of resources enhances an educator's capacity to provide a diverse range of learners with adequate agency to devise their most effective learning environments. To make the most use of such agency, however, the users must first be able to adequately engage with the resource/ technology and be aware of its potential value. Therefore, we suggest that course developers would be well advised to ensure that first-year students are adequately trained, and directed towards the use of key learning resources as well as informed of the relationship between resource use and grades. Furthermore, as resource utilisation may be linked to students' proficiency to self-regulate their learning, as suggested by prior research (Azevedo, Cromley, and Seilbert 2004; Barnard-Brak, Lan, and Paton 2010;). Therefore, mechanisms for assisting students with their development of self-directed study skills should be included in learning environment design.

Future studies would do well to look at students' demographic attributes, such as age, gender, cultural background and socio-economic status, as well as their time constraints (i.e. combining study with employment or caring responsibilities). Additionally, student and educators' familiarity with, and preference for engaging with, online resources should be identified. Such knowledge would further enhance educators' capacity to develop, implement and promote the most suitable resources that are both relevant and cost- and time-effective. Adequate awareness of the digital literacy levels of academic staff would also help institutions develop professional development programmes that address all levels of staff capacity while maximising the effective use of virtual learning environments. The "bells and whistles" provided music to some SOC students' ears and visual guidance to many MIC students' eyes, yet regardless of the tool implemented, it was utilisation of resources, rather than technology type that positively affected many students' academic aspirations and fostered engagement in the learning process.

\section{Notes}

1. A subsection of iTunes with free recorded lectures from many prestigious universities.

2. "C-learning is most often defined as a learning process happening in virtual surrounding, in which the teacher assumes the role of not a source of knowledge, but rather a source of metaskills needed to operate on that knowledge" (Ledzinska and Postek 2010, 2). 


\section{References}

Azevedo, R., Cromley, J. G. \& Seibert, D. (2004) 'Does adaptive scaffolding facilitate students' ability to regulate their learning with hypermedia?', Contemporary Educational Psychology, vol. 29 , no. 3 , pp. $344-370$.

Barjis, J. (2003) 'An overview of virtual university studies', in Virtual Education, ed F. Albalooshi. IRM, Hershey, PA, pp. 1-15.

Barnard-Brak, L., Lan, W. Y. \& Paton, V. O. (2010) 'Profiles in self-regulated learning in the online learning environment', International Review of Research in Open and Distance Learning, vol. 11, no. 1, pp. 61-79.

Bax, S. \& Pegrum, M. (2010) 'Lurking in multicultural online educational forums: "I wasn't invited to the party", in Interaction in Communication Technologies and Virtual Learning Environments: Human Factors, ed T. Ragusa. Information Science Reference, Hershey, PA, pp. 145-159.

Betts, K., Hartman, K. \& Oxholm, C. III. (2009) 'Re-examining and repositioning higher education: twenty economic and demographic factors driving online and blended program enrolments', Journal of Asynchronous Learning Networks, vol. 13, no. 4, pp. 3-23.

Biesinger, K. \& Crippen, K. (2010) 'The effects of feedback protocol on self-regulated learning in a web-based worked example learning environment', Computers and Education, vol. 55, no. 4 , pp. $1470-1482$.

Castells, M. (2000) The information age. 3 vols. Blackwell, Oxford.

Clarebout, G. \& Elen, J. (2008) 'Tool use in open learning environments: in search of learner related determinants', Learning Environment Research, vol. 11, no. 2, pp. 163-178.

Clarebout, G. et al. (2010) 'The relationship between self-regulation and embedding of support in learning environments', Education Technology Research Development, vol. 58, no. 5, pp. 573-587.

Drabinski, E., Elizabeth Clark, J. \& Sarah, T. R. (2011) 'Introduction: shaped or shaping? The role for radical teachers in teaching with technology', Radical Teacher, vol. 90, pp. 3-8.

Exeter, D. J. et al. (2010) 'Student engagement in very large classes: the teachers' perspective', Studies in Higher Education, vol. 35, no. 7, pp. 761-7005.

Giddens, A. (1984) The constitution of society: outline of the theory of structuration, Polity Press, Cambridge.

Giddens, A. (1991) Modernity and self-identity: self and society in the late modern age, Polity Press, Cambridge.

Giddens, A. (1994) 'Living in a post-traditional society', in Reflexive Modernization: Politics, Tradition and Aesthetics in the Modern Social Order, eds U. Beck, A. Giddens \& S. Lash Polity Press: Cambridge, pp. 56-109.

Giddens, A. (2002) Runaway world: how globalisation is reshaping our lives, 2nd edn. Profile Books, London.

Grimstad, K. \& Grabe, M. (2004) 'Are online study questions beneficial?', Teaching in Psychology, vol. 31, no. 2, pp. 143-146.

Hershkovitz, A. \& Nachmias, R. (2009). 'Consistency of students pace in online learning', in Educational Data Mining 2009: 2nd International Conference on Educational Data Mining, Proceedings, eds T. Barnes, M. Desmarais, C. Romero, \& S. Ventura, pp. 71-80. Cordoba, Spain.

Johnson, M. T. (2008) 'Impact of online learning modules on medical student microbiology examinations scores', Journal of Microbiology and Biology Education, vol. 9, pp. 91.

Judd, T. \& Kennedy, G. (2010) 'A five-year study of on-campus internet use by undergraduate biomedical students', Computers and Education, vol. 55, no. 4, pp. 1564-1571.

Kuh, G. D. (2004) 'The national survey of student engagement: conceptual framework and overview of psychometric properties (National Survey of Student Engagement)', Available at: http://nsse.iub.edu/2004_annual_report/pdf/2004_conceptual_framwork.pdf

Kvavik, R. (2005). Convenience, communications and control: how students use technology, in Educating the Net Generation, eds D. G. Oblinger \& J. L. Oblinger, EDUCAUSE.

Larson, D. K. \& Chung.-Hsien, S. (2009) 'Comparing student performance: online versus blended versus face-to-face', Journal of Asynchronous Learning Networks, vol. 13, no. 1, pp. $31-42$. 


\section{A. Crampton et al.}

Ledzinska, M. \& Postek, S. (2010) 'The role of metacognition in c-learning curriculum', Problems of Education in the 21st Century, vol. 23, pp. 137-145.

McFarlin, B. K. (2008) 'Hybrid lecture-online format increases student grades in an undergraduate exercise physiology course at a large urban university', Advanced Physiology Education, vol. 32, no. 1, pp. 86-91.

Morrison, D. (2003) E-learning strategies: how to get implementation and delivery right first time, John Wiley \& Sons, London.

Nasah, A., Boaventura, D., Carolyn, K., and Soonhwa, S. (2010). 'The digital literacy debate: investigation of digital propensity and information and communication technology', Education Technology Research Development, vol. 58, no. 5, pp. 531-555.

Ragusa, A. T. \& Steinke, E. (2012) 'Studying locally, interacting globally: demographic change and international students in Australian higher education', in Computer-mediated Communication Across Cultures: International Interactions in Online Environments, eds K. St Amant \& S. KelseyIGI, Hershey, PA, pp. 344-368.

Ragusa, A. T. (2009) 'Sociological insights in structuring Australian distance education', in Encyclopaedia of Information Science and Technology, 2nd edn, ed M. Khosrow-Pour, Information Science Reference, London, pp. 3513-3519.

Ragusa, A. T. (2007) 'The impact of socio-cultural factors in multi-cultural virtual communication environments: a case example from an Australian university's provision of distance education in the global classroom', in Linguistic and Cultural Online Communication Issues in the Global Age, ed. K. St Amant, Idea Group, Hershey, PA, pp. 306-327.

Robinson, K. (2007) 'Configuring virtual learning environments to support diversity and intercultural learning', Paper presented at Education in a Changing Environment Conference, September 12-14, in Manchester, UK.

Rovai, A. P. \& Downey, J. R. (2010) 'Why some distance education programs fail while others succeed in a global environment', Internet and Higher Education, vol. 13, no. 3, pp. 141147.

Salter, D., Pang, M. Y. C., \& Sharma, P. (2009) 'Active tasks to chains use of class time within and outcomes-based approach to curriculum design', Journal of University Teaching and Learning Practice, vol. 6, no. 1: article 4. Available at: http://ro.uow.edu.au/jutlp/vol6/iss1/4

Schrader, P. G. \& Lawless, K. A. (2007) 'Dribble files: methodologies to evaluate learning and performance in complex environments', Performance Improvement, vol. 46, no. 1, pp. 4048.

Schifter, C. (2004) 'Faculty participation in DE programs: practices and plans', in The distance education evolution: issues and case studies, eds D. Monolescu, C. C. Schifter \& L. Greenwood, Information Science Publishing, Hershey, PA, pp. 1-21.

Sheard, J., Carbone, A. \& Hurst, A. J. (2010) 'Student engagement in first year of an ICT degree: staff and student perceptions', Computer Science Education, vol. 20, no. 1, pp. 1-16.

Tan, L., Wang, M. \& Xiao, J. (2010) 'Best practices in teaching online or hybrid courses: a synthesis of principles', Lecture Notes in Computer Science, vol. 6248, pp. 117-126.

Tennant, M., McMullen, C., \& Kaczynski, D. (2009) 'Learning in the digital age', in Teaching, learning and research in higher education, Routledge, Hoboken.

Tremblay, R. (2006) "Best practices" and collaborative software in online teaching, The International Review of Research in Open and Distance Learning, vol. 7, no. 1. Available at: http://www.irrodl.org/index.php/irrodl/article/view/309/486

U.S. Department of Education, Office of Planning, Evaluation, and Policy Development. (2009) Evaluation of evidence-based practices in online learning: a meta-analysis and review of online learning studies. US Department of Education, Washington, DC. Available at: http://www2.ed.gov/rschstat/eval/tech/evidence-based-practices/finalreport.pdf

Windham, C. (2005) 'The students' perspective', in Educating the Net Generation, eds D. Oblinger \& J. Oblinger, e-Educause, Washington, DC, pp. 5.1-5.16. 